Abstract ID: 32

\title{
Antidiabetic activity of curry leaves Murraya koenigii on glucose level, kidney and islets of langerhans in streptozotocin induced diabetes in rats
}

\author{
Imad M. Al-Ani ${ }^{\mathrm{a}} \mid$ Rahajoe I. Santosa ${ }^{\mathrm{b}} \mid$ Muhammad H. Yankuzo ${ }^{\mathrm{a}}$ \\ ${ }^{a}$ Department of Basic Medical Science, Kulliyyah of Medicine, International Islamic University Malaysia \\ ${ }^{b}$ Department of Pathology and Laboratory Medicine, Kulliyyah of Medicine, International Islamic \\ University Malaysia
}

Introduction: This study examined the antihyperglycemic effect of curry leaves, Murraya koenigii "MK" aqueous extract, and to examine its possible protective effects on the Islets of Langerhans and kidneys in streptozotocin (STZ) induced diabetic rats. Methods: Thirty healthy adult male Sprague Dawley rats were randomized into five groups $(n=6)$; normal control, normal treated with "MK" control, diabetic control (non-treated with "MK"), diabetic treated with $200 \mathrm{mg} / \mathrm{kg}$ MK aqueous leaf extract and diabetic treated with $400 \mathrm{mg} / \mathrm{kg} \mathrm{MK}$ aqueous leaf extract. Blood glucose levels and body weight were monitored. The animals were sacrificed on the $30^{\text {th }}$ day; the kidney and pancreatic tissues were processed for histological studies. Results: The diabetic control group significantly $(p<0.001)$ showed considerable loss of body weight and increase in blood glucose levels and degeneration of the glomeruli and renal convoluted tubules and atrophied islets with disintegration of B-cells. Treatment of diabetic rats with aqueous extract showed significant $(p<0.001)$ improvement in blood glucose levels and body weight gain. The MK extract also caused an improvement in tissue injury induced by STZ injection in the kidney and endocrine pancreas. Conclusions: These findings highlighted the beneficial effects of MK aqueous extract against cellular oxidative damage in STZ-induced diabetic rats.

KEYWORDS: Blood glucose, Body weight, Curry leaves, Islet of Langerhans, Kidney. 